\section{Inclusion of non-viable neonates in the birth record and its impact on infant mortality rates in Shelby County, Tennessee, USA}

\author{
Bryan L. Williams, Melina S. Magsumbol \\ Children's Foundation Research Center at \\ Le Bonheur Children's Medical Center, \\ Department of Pediatrics, University of \\ Tennessee Health Sciences Center, USA
}

\section{Abstract}

Rates of infant death are one of the most common indicators of a population's overall health status. Infant mortality rates (IMRs) are used to make broad inferences about the quality of health care, effects of health policies and even environmental quality. The purpose of our study was threefold: i) to examine the characteristics of births in the area in relation to gestational age and birthweight; ii) to estimate infant mortality using variable gestational age and/or birthweight criteria for live birth, and iii) to calculate proportional mortality ratios for each cause of death using variable gestational age and/or birthweight criteria for live birth. We conducted a retrospective analysis of all Shelby County resident-linked birth and infant death certificates during the years 1999 to 2004. Descriptive test statistics were used to examine infant mortality rates in relation to specific maternal and infant risk factors. Through careful examination of 19992004 resident-linked birth and infant death data sets, we observed a disproportionate number of non-viable live births ( $\leq 20$ weeks gestation or $\leq 350$ grams) in Shelby County. Issuance of birth certificates to these nonviable neonates is a factor that contributes to an inflated IMR. Our study demonstrates the complexity and the appropriateness of comparing infant mortality rates in smaller geographic units, given the unique characteristics of live births in Shelby County. The disproportionate number of pre-viable infants born in Shelby County greatly obfuscates neonatal mortality and de-emphasizes the importance of post-neonatal mortality.

\section{Introduction}

Like other types of mortality, infant mortality rates (IMRs) are confounded by case definitions, population structure and reporting accuracy. ${ }^{1-13}$ Birth and death certificates are often incomplete and inaccurate. ${ }^{8-10,14-17}$ For example, congenital anomalies are frequently underreported, while the number of prenatal visits is often over-reported. ${ }^{9,10,17}$ Valid inferences about birth outcomes from these data sources are difficult to make because of their inherent unreliability. Inconsistencies in birth certificate data can clearly yield spurious trends in IMRs. Trends in our national IMRs have suggested that something is amiss. The United States IMRs from 2001 to 2002 increased to 6.95 deaths per 1,000 live births, the first increase seen since 1958. Researchers noted an increase in early neonatal deaths among infants weighing less than $750 \mathrm{~g}(1 \mathrm{lb}, 10.5 \mathrm{oz})$. For 2002-2003, the IMR returned to its previous level of 6.84 per 1,000 live births. Yet $49 \%$ of infant deaths in 2003 occurred among infants with very low birthweight (less than $1500 \mathrm{~g}$ ). Were these real trends or artifacts of the data collection process?

IMR trends may be a function of reporting requirements. Physicians pronouncing a nonviable fetus as "born alive" further complicate reporting and may bias data. The subjective clinical determination of 'live birth' undermines the objectivity of IMRs. It must be noted that infant mortality represents a rare event in most industrialized countries. Consequently, IMRs are easily affected by the addition or subtraction of even one infant death. Being a rare event, it is highly subject to random error.

Inconsistent interpretation of 'live birth' is not trivial. The over-reporting of live births among extremely preterm, non-viable infants has far-reaching implications. First, an increase in reported live births among nonviable infants artificially inflates IMRs and deflates fetal death rates. Second, such overreporting also skews the relative importance of each cause of infant death. The cause of death for the vast majority of non-viable infants is extreme prematurity, thus overshadowing less prevalent causes of death such as unintentional injury. This is important since proportionate mortality estimates are frequently used to prioritize public health efforts. For example, the leading cause of adult mortality, heart disease, receives considerably more attention from the public health sector than do motor vehicle accidents. Similarly, changes in IMRs may influence the public health efforts focused on preventing infant mortality and take away from the efforts focused on preventing fetal deaths. Despite the efforts to standardize the operational definition of 'live birth', considerable variability among states remains.

\section{Live birth, fetal death and infant death}

What is considered a live birth? Although one might think that this is a simple clinical assessment, it is not. Live birth is defined as "the complete expulsion or extraction from its mother of a product of conception, irrespective
Correspondence: Bryan L. Williams, Associate Dean for Research, Georgia State University, PO Box 3980, Atlanta, GA, USA.

E-mail: bryanw56@gsu.edu

Key words: infant mortality rates, fetal death, viability, extreme prematurity, African-American neonates.

Contributions: BLW conceived the study, drafted the manuscript and performed data analysis and interpretation; MSM managed the data, helped draft and revise the manuscript. Both authors read and approved the final manuscript.

Acknowledgements: the authors would like to acknowledge the significant contribution of their colleague Ms. Takita Griffin. This study would not have been possible without her.

Conflict of interest: the authors report no conflicts of interest.

Received for publication: 30 November 2009 Accepted for publication: 27 January 2010.

This work is licensed under a Creative Commons Attribution 3.0 License (by-nc 3.0).

(C) Copyright B.L. Williams and M.S. Magsumbol, 2010 Licensee PAGEPress, Italy

Pediatric Reports 2010; 2:e1

doi:10.4081/pr.2010.e1

of the duration of the pregnancy, which, after such separation, breathes or shows any other evidence of life such as heartbeat, umbilical cord pulsation or definite movement of voluntary muscles, whether the umbilical cord has been cut or the placenta is attached. Each product of such a birth is considered live born."

Some states have added language to help clarify various aspects of this definition. For example, Tennessee recently added, 'Heartbeats shall be distinguished from transient cardiac contractions and respirations shall be distinguished from fleeting respiratory efforts or gasps" [Tenn Code: 68-3-102(9)]. The expanded definition was added in the hope to improve the classification of live births vs fetal deaths. Despite the directives, the etiology and the incidence of fetal deaths are under-studied. ${ }^{19}$

In practice, it is difficult to find any 'evidence of life' in an infant whose vital bodily systems have just begun to develop. Extremely premature infants often will meet only the most minimal requirements of 'live birth', such as a transient heartbeat. The clinical criteria for differentiating between a fetal death and live birth are paradoxical. That is, an extremely premature birth (i.e., 17 weeks) can be designated as 'born alive' even though its gestational age and/or birthweight do not meet the minimal requirements (i.e., $\geq 22$ weeks or 
$\geq 500$ grams) for reporting of fetal deaths in Tennessee. The burden of proof for declaring a live birth is rather low, considering also that heartbeats are detectable at embryonic stages. ${ }^{20}$ By these criteria an 8 -week-old fetus that sustained a heartbeat long enough to pass through the birth canal could be considered a live birth. There is increasing evidence that treatment of extremely premature infants (<23 weeks) has become more aggressive. ${ }^{21}$ Additionally, there is mounting pressure on physicians to perform extraordinary measures on infants pushing the extreme limits of viability. ${ }^{22-25}$ The American Academy of Pediatrics has stood strong in the face of this pressure, stating that "...the law does not proscribe medical care for newly born infants delivered at the limits of viability." ${ }^{26}$ The aggressive treatment and resuscitation of marginally viable and non-viable infants have long been a contentious issue. While the long-term prognosis for an extremely premature infant is frequently very poor ${ }^{27}$ and the medical costs are enormous, ${ }^{28}$ the viability "gray zone" for mandating care is ever decreasing. ${ }^{22,23}$

\section{Memphis, TN: the infant mortality capital?}

One study showed that among the 60 largest United States cities, Memphis had the highest IMR from 1995 to 1998, with 15.4 per 1,000 live births. ${ }^{29}$ Disparate IMRs have also been observed within the city. IMR among the city's African-American population have exceeded 17 per 1,000 live births, more than twice the national rate. Teen pregnancy, hazardous waste sites, poor prenatal care and substance abuse were only some of the factors that stakeholders pointed to as the culprits. The public outcry in Memphis and sensational media coverage naturally resorted to a spike in community summits, task forces and intervention programs. All of this is expected, but a critical review of the mortality data never ensued. In fact, the child death review team, of which the authors were member, would regularly review deaths of extremely premature infants $(\leq 20$ weeks) most weighing less than 350 grams. There was clearly an issue with reporting requirements.

The fact that Memphis infants were dying at alarming rates was taken at face value. The veracity of the data went unquestioned, thus ignoring the reality that birth and death records are notoriously inaccurate and incomplete. ${ }^{1,630-33}$ Were IMRs really excessive? If so, why would these rates be so much higher than those observed in comparable populations? The lack of any meaningful analysis of these data prompted us to take a closer look. The purpose of our study was threefold: i) to examine the characteristics of births in the area in relation to gestational age and birthweight; ii) to estimate infant mortality using variable gesta- tional age and/or birthweight criteria for live birth, and iii) to calculate proportional mortality ratios for each cause of death using variable gestational age and/or birthweight criteria for live birth.

\section{Materials and Methods}

We analyzed linked resident birth and infant death certificate data for the years 1999-2004 in Shelby County, Tennessee. This is an exempt study approved by the Internal Review Board of the University of Tennessee Health Science Center. This data set included 86,052 live births and 1,130 recorded infant deaths. We used 'clinical estimate' of gestational age rather than 'date of last normal menses' (LMP) for data analysis, despite the fact that LMP estimates are advocated in the literature. ${ }^{3,34,35}$ The extent to which the 'clinical estimate' (e.g., early ultrasound) is a more accurate measure of gestational age than the selfreported date of last menses is unclear.,34,35 However, in Shelby County, LMP is much less likely to be reported on the birth certificate than is the clinical estimate.

The linked birth-death data file was systematically reviewed by a nurse practitioner, a maternal and fetal medicine specialist physician and an epidemiologist, who is a member of the Shelby County Child Death Review Team. The review panel reviewed all 1,130 infant deaths for the following: i) missing gestational age or birthweight data; ii) accuracy of maternal risk factor data; iii) the likelihood of the primary cause of death given the observed infant and maternal risk factors; and iv) maternal residence. The panel identified cases that were problematic with respect to the aforementioned areas. Hard copies of both the birth and death certificates were consulted for the identified cases and the electronic data were corrected or completed for the cases. The research team checked the original birth and death certificates at the Memphis and Shelby County Health Department to verify data for cases that had missing variables or questionable data.

\section{Handling of missing data}

We established protocols for handling the cases for which estimates of gestational age and/or birthweight were missing. Approximately $2.1 \%$ of our sample was missing both a clinical estimation (CE) of gestational age and the LMP. Additionally, two infants in the sample (infant deaths) did not have a recorded birthweight. The CE was used as the primary variable for gestational age, when available, as less than $1 \%$ of these estimates was missing, whereas $21 \%$ of the live birth records and $28 \%$ of the infant death cases were missing an LMP estimate. Excluding close to one third of the infant deaths will artificially deflate the overall IMRs, when examined in relation to gestational age.

For cases that were missing both the CE and LMP, we compiled all single births from 19992004 and used the $50^{\text {th }}$ percentile of birthweights per each gestational age. We used the lower-bound value closest to the infant's birthweight and utilized it as the assigned gestational age. The use of CE may pose a source of bias for this study, ${ }^{36,37}$ but we contend that the use of LMP would bias our estimates even more. Missing data posed a significant limitation for this study. Obtaining accurate estimates of gestational age is especially problematic in an urban population of poorly educated women. There is often a poor clinical documentation of their pregnancy because of their lack of prenatal care. ${ }^{38}$ Both LMP and clinical estimates of gestational age are known to be particularly inaccurate among this population. ${ }^{39}$ Among our sample, LMP estimates were noticeably incomplete and implausible. This is problematic because LMP estimates are likely to be more standardized than what clinical estimates are. Hence, estimates of mortality by gestational age should be interpreted with caution.

\section{Results}

\section{Sample characteristics}

The sample for this study was comprised of 86,052 live births and 1,130 infant deaths from 1999 to 2004. The median age of mothers in the sample was approximately 26 . About $44 \%$ of mothers had some college education while $51 \%$ had at least some education beyond the $9^{\text {th }}$ grade. The remaining $4 \%$ of mothers had only elementary school education or less. About $34 \%$ of the infants were Caucasian nonHispanic, 58\% were African-Americans, 6\% were Hispanic and the remaining $2 \%$ were of another ethnicity.

\section{Distribution of Shelby County births by gestational age}

In the first analysis we examined the distribution of births in Shelby County from 2003 to 2004 by gestational age and birthweight. We compared the Shelby County distribution with that of the national distribution of births in the U.S. from 2003 to 2004. Figure 1 compares the distribution of births by gestational age in Shelby County to that of the United States.

Almost four times as many infants were born in Shelby County before 20 weeks gestation than were born in the U.S. during this time period $(\mathrm{P}<0.001)$. Almost twice as many $(\mathrm{OR}=1.74)$ infants were born in Shelby County between 20-27 weeks gestation as well 
$(\mathrm{P}<0.001)$. The distribution of births for the two areas was strikingly similar between $28-40$ weeks gestation. The distribution of Shelby County births between 28-36 weeks did not differ significantly from that of the national distribution of births. However, significantly fewer Shelby County infants were born after 40 weeks gestation than that observed nationally.

\section{Distribution of Shelby County births by infant birthweight}

A disproportionate number of infants were born at low gestational ages in Shelby County. The high proportion of prematurity negatively skews the distribution of infant birthweights. We compared the Shelby County distribution of births by birthweight with that of the national distribution in the U.S. from 1999 to 2004. This is perhaps a better comparison of the two birth distributions, since birthweight is a more objective measure than gestational age. Figure 2 illustrates this comparison.

As seen in Figure 2, the Shelby County distribution of births by birthweight varies significantly from the one of the national distribution during the same time period. The largest difference between the two groups was among births equal to or below 499 grams. Almost 3.5 times as many infants were born in Shelby County at less than 500 grams birthweight than were born in the U.S. during this time period $(\mathrm{P}<0.001)$. About 1.78 times more infants were born in Shelby County between 500 and 999 grams birthweight $(\mathrm{P}<0.001)$. The only birthweight category in which Shelby County births did not significantly differ was 3,000-3,499 grams. Overall, a disproportionately high number of low birthweight infants were born in Shelby County during this time period.

\section{IMRs in Shelby County by birthweight}

As observed in Figures 1-2, the proportion of prematurity and low birthweight among Shelby County infants during this five-year period was quite high when compared to the one of the U.S. Since birthweight is known to influence infant survival, we examined the birthweightspecific IMR and then compared it with that of the U.S. Figure 3 compares the IMR by birthweight between Shelby County and the U.S.

In most birthweight categories, Shelby County IMRs were not significantly different from the U.S. rates. Mortality rates of infants born below 2,500 grams were remarkably similar to those of the United States. Although not statistically significant, Shelby County infants born between 500-999 grams were 8\% less likely to die than their U.S. counterparts. The two distributions also did not differ significantly in mortality among infants weighing 4,000 grams or more. The most notable difference between the two distributions was among infants weighing between 2,500 and 3,999 grams. In

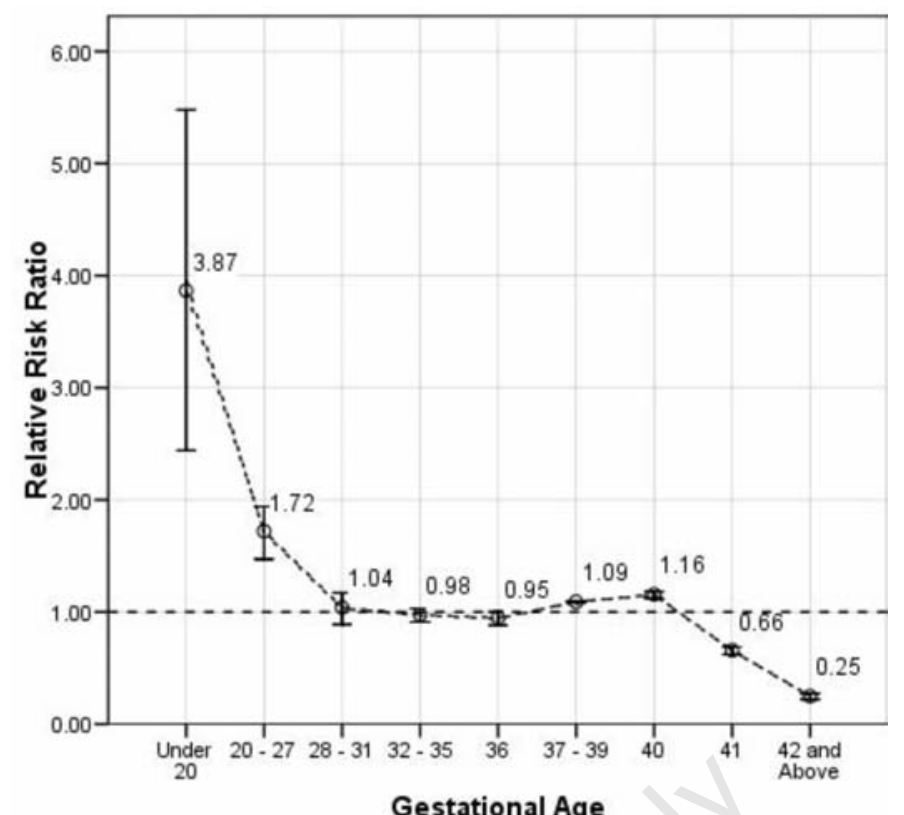

Figure 1. Comparison of 20032004 distribution of births by gestational age in Shelby County, TN $v$ s the U.S. The clinical estimate was used for gestational age for Shelby County births; for the national distribution the date of last menses estimation was used.

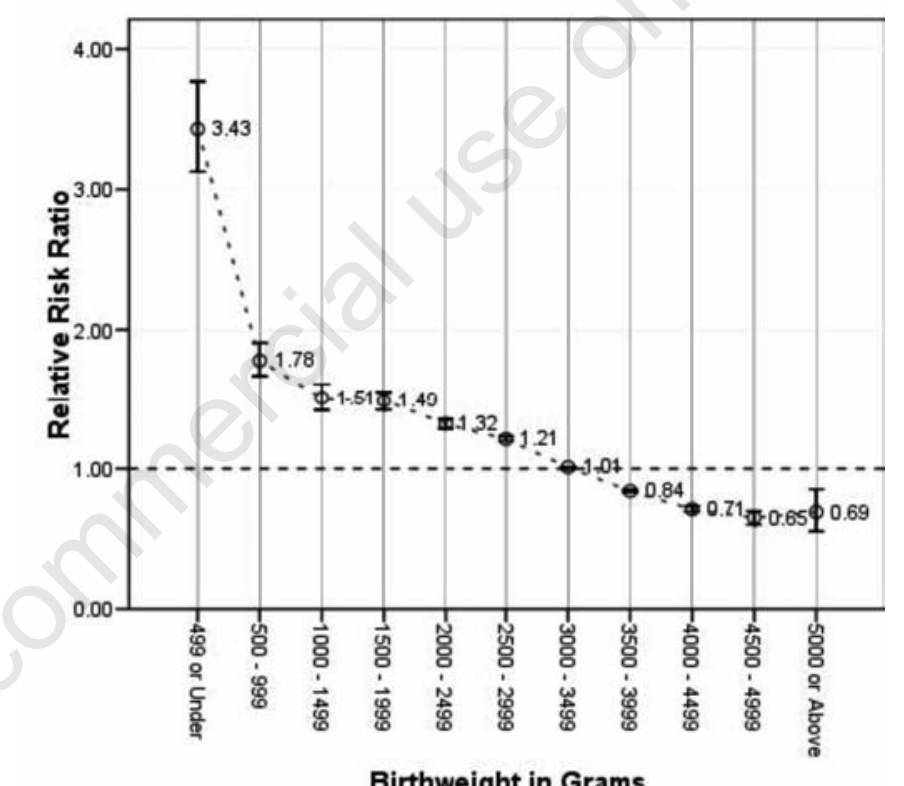

Figure 2. Comparison of 1999 . 2004 distribution of births by birthweight in Shelby County, TN $v s$ the U.S.

both birthweight categories, Shelby County infants were about $38 \%$ more likely to die than U.S. infants.

\section{Birthweight standardized IMRs}

The population structure of Shelby County births with respect to birthweight is substantially different from that of the United States. This population difference confounds comparisons of overall infant mortality between the United States and Shelby County. Therefore, we directly standardized the Shelby County births to the U.S. births to allow a more precise comparison of mortality rates.

Direct standardization is used effectively to compare IMR between two birth distributions that differ significantly in composition (e.g., birthweight). ${ }^{2}$ Figure 4 compares IMR in
Shelby County vs the U.S. using both crude and adjusted mortality rates. The Shelby County rates were directly adjusted to the 2004 distribution of live births in the U.S. by birthweight using 500 gram increments ranging from 499 grams to above 5,000 grams. The tables and numbers used for the direct standardization are provided in Appendix A.

As shown in Figure 4, the birthweight composition of Shelby County significantly influences IMRs. The IMR in Shelby County drops by $39.9 \%$ when the birth distribution is adjusted to that of the U.S. Thus, excess infant mortality in Shelby County is largely a function of its unique distribution of birthweights. As shown in Figure 2, the most unique aspect of the distribution of Shelby County births is the inexplicable proportion of infants born below 
500 grams. The births of these extremely premature infants clearly inflate overall infant mortality in this area.

\section{Impact of extreme low birthweight on overall infant mortality in Shelby County (2003-2004)}

A closer examination of births and deaths in Shelby County from 2003 to 2004 indicates that most of the excess infant mortality can be attributed to "extreme prematurity". During this two-year period there were approximately 68 live births of infants weighing less than or equal to 350 grams. The 68 births in this category accounted for $0.24 \%$ of the total live births in Shelby County during this two-year period. None of the 68 infants survived and thus they accounted for $18 \%$ of the total number of infant deaths. This is very different from the U.S. distribution during this period. In the United States, 4,887 births accounted for $0.06 \%$ of the total live births during this period. The 4,342 deaths accounted for only about $8 \%$ of the total number of infant deaths nationwide. Hence, in Shelby County, extremely low birthweight infants account for almost four times the total number of live births and about twice the number of infant deaths when compared with the U.S. births in this category. Moreover, for birthweights 350 grams or under, Shelby County accounted for about $1.4 \%$ of total infant births and $1.6 \%$ of total infant deaths in the entire United States during the 2003-2004 period. The relative risk of death for these infants differs only marginally. Shelby County infants showed only about a $6 \%$ increase in risk of death, which was not statistically significant.

Live births of infants weighing 350 grams or less have a profound effect on infant mortality in Shelby County. Figure 5 illustrates the impact that extremely low birthweight infants have on overall and neonatal mortality rates in Shelby County.

The aggregated neonatal death rate (deaths of infants $\leq 28$ days old) was approximately 9.3 per 1,000 live births. In contrast, the aggregated post-neonatal death rate (deaths of infants surviving $>28$ and $<365$ days) was approximately 3.9 per 1,000 live births. When infants weighing 350 grams or less are excluded from the analysis the IMR drops by almost $17 \%$ and the neonatal rate drops by almost $24 \%$. If we had used a minimal gestational age criteria, the neonatal death rate would have dropped to about 4.8 per 1,000 live births, if all births less than 22 weeks gestational age were excluded; a $48.4 \%$ decrease. Most notably, the postneonatal death rate for African-American infants was approximately 5.4 per 1,000 live births, whereas for Caucasian infants it was 1.6 per 1,000 live births.

About $71 \%$ of the infant deaths stem from neonatal mortality as opposed to about $67 \%$

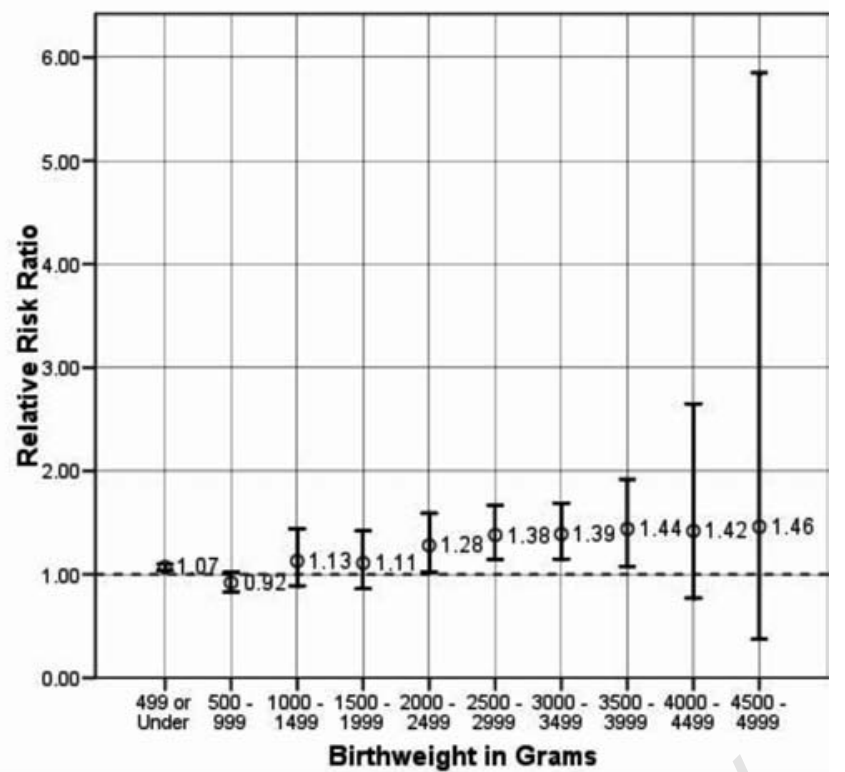

Figure 3. Relative risk of infant death by birthweight for Shelby County $v s$ the U.S. from 1999 to 2004.

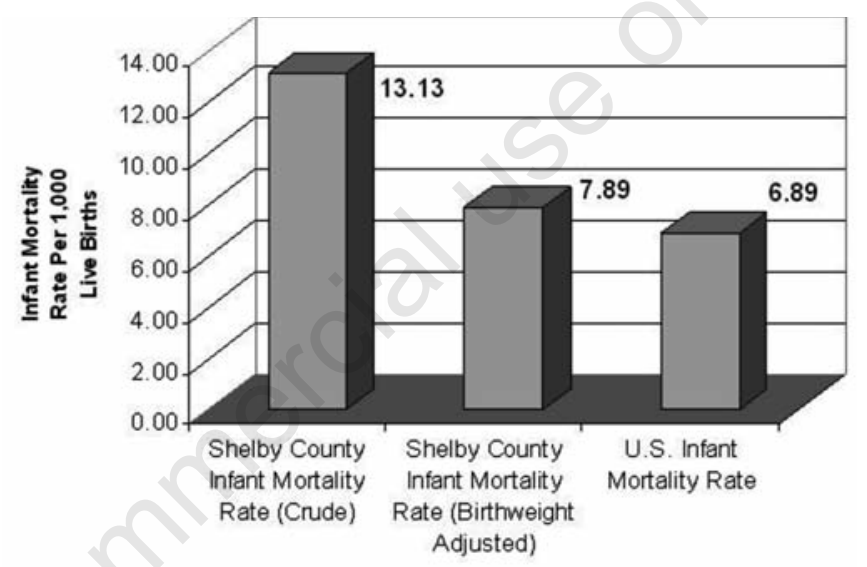

Figure 4. Crude and birthweightadjusted IMRs (1999-2004) in Shelby County, TN compared with U.S. IMRs (2004).

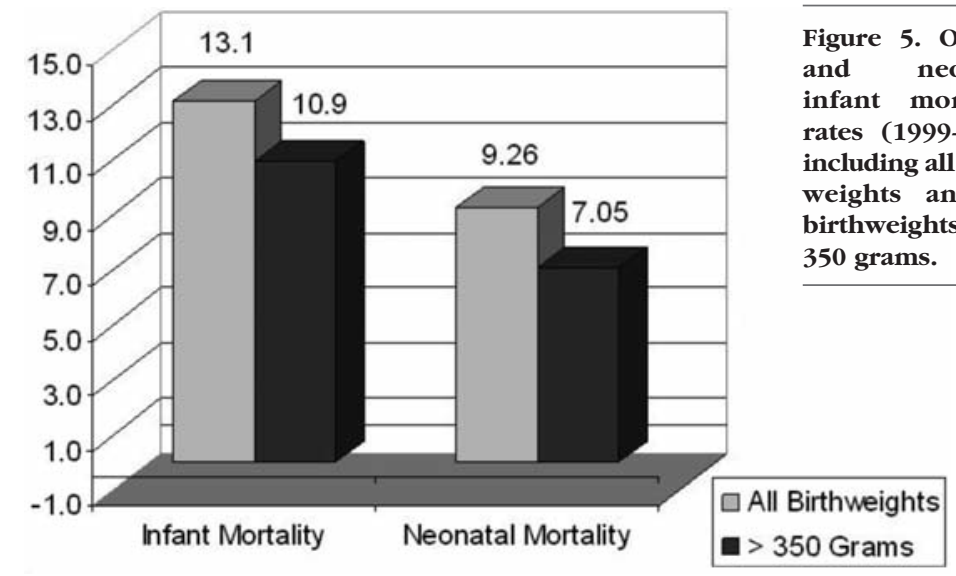

nationally. ${ }^{40}$ The neonatal mortality rate in Shelby County of 9.3 per 1,000 live births is over twice the national rate in 2004 of 4.5 per 1,000 live births. The post-neonatal mortality rate of 3.9 per 1,000 live births is 1.7 times the national rate of 2.25 per 1,000 live births in $2004{ }^{40}$ The post-neonatal death rates for African-American and Caucasians were fairly similar to the national average. The postneonatal death rate for Caucasians was about $19 \%$ lower than the national average, while the rate for African-American infants was about $19 \%$ higher than the national average. The effect of including previable infants as live births is better illustrated using both gestational age and birthweight criteria for inclu- 
Table 1. Proportional mortality ratio of underlying cause of death per gestational age in Shelby County, TN, $1999-2004$.

\begin{tabular}{|c|c|c|c|c|c|c|}
\hline \multirow{2}{*}{$\begin{array}{l}\text { Underlying cause } \\
\text { of death } \\
(I C D-10)\end{array}$} & \multicolumn{2}{|c|}{$\begin{array}{l}\text { All infant } \\
\text { deaths }\end{array}$} & \multicolumn{2}{|c|}{$\begin{array}{c}22 \text { weeks } \\
\& \text { above }\end{array}$} & \multicolumn{2}{|c|}{$\begin{array}{l}24 \text { weeks } \\
\& \text { above }\end{array}$} \\
\hline & $\mathbf{N}$ & $\%$ & $\mathbf{N}$ & $\%$ & $\mathbf{N}$ & $\%$ \\
\hline Congenital malformation/deformation, chromosomal abnormalities [Q00-Q99] & 153 & 13.54 & 149 & 17.91 & 147 & 22.24 \\
\hline Disorders due to short gestation [P07] & 320 & 28.32 & 96 & 11.54 & 20 & 3.03 \\
\hline SIDS [R95] & 113 & 10.00 & 113 & 13.58 & 113 & 17.10 \\
\hline Newborn affected by maternal complications of pregnancy [P01] & 27 & 2.39 & 12 & 1.44 & 5 & 0.76 \\
\hline Newborn affected by complications of the placenta, cord, membranes [P02] & 19 & 1.68 & 17 & 2.04 & 15 & 2.27 \\
\hline Accidents (unintentional injuries) [V01-X59] & 48 & 4.25 & 48 & 5.77 & 48 & 7.26 \\
\hline Respiratory distress of newborn [P22] & 51 & 4.51 & 47 & 5.65 & 27 & 4.08 \\
\hline Bacterial sepsis of newborn [P36] & 30 & 2.65 & 29 & 3.49 & 24 & 3.63 \\
\hline Diseases of circulatory system [i00-i99] & 17 & 1.50 & 17 & 2.04 & 17 & 2.57 \\
\hline Intrauterine hypoxia and birth asphyxia [P20-P21] & 19 & 1.68 & 18 & 2.16 & 16 & 2.42 \\
\hline All other causes & 332 & 29.38 & 285 & 34.25 & 228 & 34.49 \\
\hline Total & 1129 & 99.91 & 831 & 99.88 & 660 & 99.85 \\
\hline Unknown & 1 & 0.09 & 1 & 0.12 & 1 & 0.15 \\
\hline Total & 1130 & 100.00 & 832 & 100.00 & 661 & 100.00 \\
\hline
\end{tabular}

sion. We estimated infant mortality using variable gestational age and/or birthweight criteria for live birth. Figure 6 shows the aggregate IMRs in Shelby County from 1999 to 2004 using the following four birthweight and gestational age cut-offs: i) all gestational ages and birthweights designated as a 'live birth'; ii) infants born on or after 22 weeks gestation; iii) infants born on or after 24 weeks gestation; and iv) infants born on or after 24 weeks gestation and whose birthweight was 500 grams or higher. As illustrated in Figure 6, the IMR changes substantially depend on the criteria used for live birth. The IMR observed in Shelby County is approximately 13.13 per 1,000 live births. It has to be noted that the rate drops by $25 \%$ from 13.1 to 9.7 by excluding infants born before 22 weeks. If only infants with a gestational age of $\geq 24$ weeks are included, there is a $41 \%$ reduction in the mortality rate (from 13.13 to 7.72 per 1,000 births). Furthermore, the rate drops to 7.33 per 1,000 live births if only infants with a gestational age of 24 weeks and above and a birthweight of at least $500 \mathrm{~g}$ are included.

\section{Proportional mortality ratio of underlying cause of death, 1999-2004}

We calculated proportional mortality ratios for each cause of death using variable gestational age and/or birthweight criteria for live birth. Table 1 provides proportional mortality ratios for the leading 10 causes of infant death in the U.S. using the International Classification of Disease (ICD), $10^{\text {th }}$ revision. ICD-10 codes represent the underlying cause of death from 1999 to present days.

As was observed with the IMRs, varying the

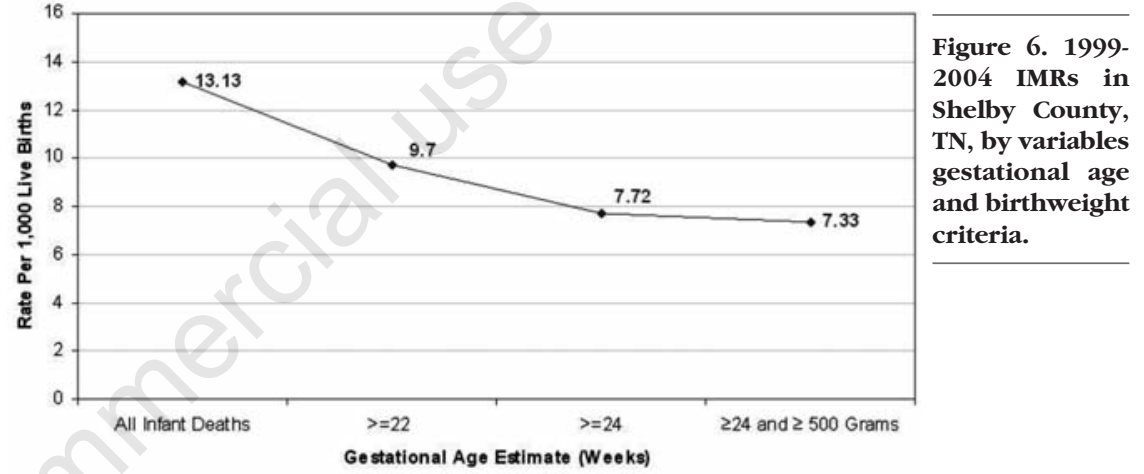

inclusion criteria greatly affects the proportional mortality ratios. Most notably, deaths from 'disorders due to short duration' drop sharply from $28.3-3.03 \%$ of total deaths. When births before 24 weeks are excluded, the percentage of infant deaths due to extreme prematurity drops by $89 \%$. The relative rank is changed for several of the underlying causes of death depending on the inclusion criteria. From 1999 to 2004, infants who were born prematurely or with low birthweights accounted for $28 \%$ of the deaths in the sample, congenital malformations or chromosomal abnormalities accounted for approximately 14\%, while SIDS accounted for $10 \%$ of all infant deaths. If we only included infants with a gestational age of $\geq 22$ weeks (subgroup I), deaths due to congenital malformations or chromosomal abnormalities accounted for the largest portion of deaths (18\%). The number of SIDS deaths, while constant, accounted for $14 \%$ of the cases. Deaths due to prematurity or low birthweight decreased accordingly (12\%). If only infants with a gestational age of $\geq 24$ weeks are included (subgroup II), congenital malformations and chromosomal abnormalities accounted for $23 \%$ of the deaths, while SIDS accounted for $17 \%$ of the deaths. The downward trend for deaths due to prematurity or low birthweight continues as gestational age increases, accounting only for $3 \%$ of the cases.

\section{Discussion}

The distribution of births in Shelby County is quite unique with respect to both birthweight and gestational age. The high incidence of extreme low birthweight and prematurity among these infants contributes greatly to the high rate of infant mortality in the area. However, the observed excess of infant mortality in Shelby County does not necessarily indicate that our infants are unhealthy or that our public health system has somehow failed 
Appendix A. Direct standardization of Shelby County IMRs to U.S.

\begin{tabular}{|c|c|c|c|c|c|}
\hline Birthweight interval & Index events (deaths) & Index PT (births) & Index rate & Reference size & Weight \\
\hline 499 or less & 406 & 443 & 916.5 & 6282 & 0.002 \\
\hline 500-999 & 251 & 868 & 289.2 & 23433 & 0.006 \\
\hline $1000-1499$ & 62 & 951 & 65.2 & 30925 & 0.008 \\
\hline 1500-1999 & 60 & 1960 & 30.6 & 65691 & 0.016 \\
\hline $2000-2499$ & 79 & 5442 & 14.5 & 205441 & 0.050 \\
\hline 2500-2999 & 108 & 17801 & 6.1 & 729675 & 0.178 \\
\hline $3000-3499$ & 103 & 32655 & 3.2 & 1573189 & 0.383 \\
\hline $3500-3999$ & 47 & 20306 & 2.3 & 1124630 & 0.274 \\
\hline $4000-4499$ & 10 & 4855 & 2.1 & 299081 & 0.073 \\
\hline 4500-4999 & 2 & 689 & 2.9 & 44889 & 0.011 \\
\hline $5000-8165$ & 2 & 82 & 24.4 & 5007 & 0.001 \\
\hline Total & 1130 & 86052 & & 4108243 & \\
\hline
\end{tabular}

Rates are expressed per 1,000 units of person time

Adjusted events $=678.729589 \quad$ Crude rate $=13.131595$

Adjusted rate $\mathrm{R}=7.887435$

Approximate standard error of $R=0.242259$

Approximate 95\% confidence interval $=7.412617$ to 8.362254

Small rates (Poisson model)

Approximate standard error of $R=0.258603$

them. Our study has shown that first year survival among low birthweight and preterm infants rival that of any infant born throughout the U.S. Our study has also shown that it is difficult, if not misleading, to compare infant mortality in this area with other areas, given the unique characteristics of Shelby County births.

The characteristics of Shelby County births are so different from those of the whole U.S. that it is reasonable to question the validity of infant mortality estimates. The likelihood of having an unquestionably non-viable $(\leq 20$ weeks gestation or $\leq 350$ grams) live birth in Shelby County is about four times higher than the U.S. average, thus greatly inflating its overall infant mortality. This proportion of infant births represent somewhat of a "fixed' component of the infant mortality equation in Shelby County. A relatively constant number of these extremely premature and low birthweight infants are born each year, none of which survive. Consequently, a substantial decrease in infant mortality is unlikely, if the high risk characteristics of the births remain stable. This begs the question: are the unique characteristics of births in Shelby County real or artifactual? Though difficult to demonstrate empirically, it is plausible to suggest the possibility of classification bias that is inherent to Shelby County. Clinicians in this area may be uniquely inclined to classify a birth as 'live'. The high proportion of non-viable births may place an unusual burden on and thus bias clinical decisions in this instance. As the number of pre-viable births increases, so does the number of requisite subjective clinical decisions. Ascertaining 'signs of life' coming from a $350 \mathrm{~g}$ infant is at least difficult. These highly subjective clinical decisions increase the potential for clinical errors or biases. A physician may decide to err by excessive caution, if clinical signs of life are ambiguous, thus resulting in an over-reporting of live births.

The disproportionate number of pre-viable infants born in Shelby County greatly obfuscates neonatal mortality and de-emphasizes the importance of post-neonatal mortality. On the surface, it would appear neonatal mortality is more of a concern than what post-neonatal mortality is. However, neonatal mortality may be artificially inflated by the inclusion of previable infants. If we simply exclude pre-viable infants ( $\leq 22$ weeks gestation), neonatal mortality rates in Shelby County are almost identical to the U.S. In contrast, post-neonatal mortality rates are a more objective indicator, as they are not influenced by classification bias. Arguably, excessive post-neonatal mortality in this region represents a bigger concern than what neonatal mortality does. Intervention efforts targeted toward the post-neonatal period might be more successful in reducing overall infant mortality. Post-neonatal mortality often results from more preventable causes of death, including unintentional injury and sudden infant death syndrome.

The distinct characteristics of births in Shelby County also affect estimates of causespecific infant mortality. Although prematurity appears to be the leading cause of infant death, congenital anomalies should not be ignored. Two factors suggest that congenital anomalies may be the most prominent cause of death among this group. First, birth defects can be grossly under-reported on birth and death certificates. ${ }^{41-44}$ Even birth defects registries can under-report birth defects by as much as $13 \%{ }^{44}$ Consequently, we may greatly underestimate their importance as an underlying cause of death. Second, fetal abnormalities are known to increase the likelihood of prematurity. A fetus with a birth defect may be almost 12 times more likely to deliver before 32 weeks gestation. ${ }^{45}$ Both factors are true irrespective of what gestational age criteria are used for 'live birth.' Increasing the gestational age criteria for a 'live birth' only serves to magnify the importance of congenital anomalies as a cause of death

This analysis demonstrates just how easy it is to misinterpret crude mortality rates. Unadjusted mortality rates are biased by several factors, including unique population distributions. For example, according to crude mortality rates Florida was one of the 'most deadly' states in the U.S. from 1999 to $2004 .^{46}$ Furthermore, crude mortality rates in Florida are almost twice that the ones of Mexico. ${ }^{47}$ However, old age, not some mysterious killer, is attributable for the excess deaths in Florida. Since Florida's population is largely older than Mexico's, crude mortality rate comparisons between the two areas are misrepresentative. Adjusting for differences in the age composition permits a more valid comparison between the two mortality rates. Crude IMRs provide no exception. Variability in population characteristics (e.g., fertility rates or 
birthweight distribution) limits the ability to make reliable geographic comparisons. Additionally, inconsistencies or biases in the reporting of 'live births' between two given regions will result in erroneous comparisons. We assert that the unique characteristics of births in Shelby County complicate even the most basic of comparisons with other localities.

\section{Conclusions}

IMRs are one of the most widely used indicators of 'need' in the public health sector. Memphis's rates imply that the needs of its infants are greater than the ones of even some of the most economically and socially deprived third world nations. The rates also imply that health care and prevention efforts are inferior to that of some developing countries. An objective review of infant mortality in this area demonstrates that neither implication is accurate. Researchers have long acknowledged that international comparisons are intrinsically unreliable. ${ }^{48-50}$ Registration of live births, fetal deaths and infant deaths in developing nations are typically very different from that in the U.S. and thus do not allow for meaningful comparisons. $^{48-50}$ While state-to-state comparison of infant mortality has its limitations, international comparisons are relatively useless.

Infant mortality has long been the bane of Memphis' existence. A 1936 report reads, "Local concern over this situation led to a request to the United States Children's Bureau to make a study of the causes of the high IMR of Memphis and recommendations as to measures for decreasing it. ${ }^{151}$ The Child Bureau even pointed out that the local rates of infant mortality are misrepresentative because the city cares for many mothers who live in the border states of Arkansas and Mississippi ${ }^{51}$ The impetus for and the findings of this early $20^{\text {th }}$ Century report are eerily similar to publications and local newspaper headlines over the past few years. While fervour for this problem has remained steadfast over the years, so has the distortion of the statistics. Easily quantified and graphically displayed, IMRs can take on a life of their own. This is how places like 38108 become the "most deadly zip code in America, ${ }^{, 52}$ a characterization that is both inaccurate and unfairly stigmatizing. Despite the hyperbole of the media, there is a strong argument to be made that infant mortality, particularly in an urban environment, is a very poor indicator of a population's health. ${ }^{53}$ Like adult mortality, infant mortality has a complex and frequently elusive etiology. IMRs alone, particularly in Shelby County, tell us very little about our children's health. Adult mortality rates seldom provide the basis for establishing task forces or political mandates. Rather, we use this information to identify, prioritize and target preventable causes of adult mortality. Infant mortality should be addressed in the same manner. Researchers and practitioners alike should be reminded that just because a number can be mapped, graphed or sell newspapers does not mean it is meaningful.

\section{References}

1. Northam S, Knapp TR. The reliability and validity of birth certificates. J Obstet Gynecol Neonatal Nurs 2006;35:3-12.

2. MacDorman MF, Martin JA, Mathews TJ, et al. Explaining the 2001-02 infant mortality increase: data from the linked birth/infant death data set. Natl Vital Stat Rep 2005;53: 1-22.

3. Balchin I, Whittaker JC, Steer PJ, Lamont RF. Are reported preterm birth rates reliable? An analysis of interhospital differences in the calculation of the weeks of gestation at delivery and preterm birth rate. BJOG 2004:111:160-13.

4. Kirby RS. Invited commentary: using vital statistics databases for perinatal epidemiology: does the quality go in before the name goes on? Am J Epidemiol 2001;154: 889-90.

5. Joseph KS, Kramer MS, Allen AC, et al. Implausible birth weight for gestational age. Am J Epidemiol 2001;153:110-113.

6. Adams M. Validity of birth certificate data for the outcome of the previous pregnancy, Georgia, 1980-1995. Am J Epidemiol 2001; 154:883-8.

7. Kirby RS. The quality of vital perinatal statistics data, with special reference to prenatal care. Paediatr Perinat Epidemiol 1997;11:122-8.

8. Farley D0, Richards T, Bell RM. Effects of reporting methods on infant mortality rate estimates for racial and ethnic subgroups. J Health Care Poor Underserved 1995;6:6075 .

9. Snell LM, Little BB, Knoll KA, et al. Reliability of birth certificate reporting of congenital anomalies. Am J Perinatol 1992; 9:219-22.

10. Hexter AC, Harris JA. Bias in congenital malformations information from the birth certificate. Teratology 1991;44:177-80.

11. Pinnelli A. Record linkage in the study of infant mortality: some aspects concerning data quality. Statistica 1984;44:675-86.

12. Piasecki E. The impact of deviations from the definition of live births on the rate of infant mortality. Wiadomości statystyczne 1984;29:5-6.

13. Gomez Redondo R. Actual infant mortality compared with legal infant mortality. Bol Asoc Demogr Hist 1984;2:6-19.
14. Dietz PM AM, Kendrick JS, Mathis MP. Completeness of ascertainment of prenatal smoking using birth certificates and confidential questionnaires: variations by maternal attributes and infant birth weight. PRAMS Working Group. Pregnancy Risk Assessment Monitoring System. Am J Epidemiol 1998; 148:1048-1054.

15. Germain JM, Czernichow P, Josset V, et al. Quality of data acceptable for perinatal epidemiology surveillance: assessment of the health certificate at birth and the national obstetrics medical file. Study in three Seine-Maritime maternal wards. J Gynecol Obstet Biol Reprod 1998;27:384-8.

16. McDermott J, Drews C, Green D, Berg C. Evaluation of prenatal care information on birth certificates. Paediatr Perinat Epidemiol 1997;11:105-21.

17. Shaw GM, Malcoe LH, Croen LA, Smith DF. An assessment of error in parental occupation from the birth certificate. Am J Epidemiol 1990;131:1072-9.

18. NCHS, Statistics NCfH. NCHS Data Definitions. Volume 2007. Bethesda, MD: U.S. Health and Human Services; 2007.

19. Silver RM, Varner MW, Reddy U, et al. Workup of stillbirth: a review of the evidence. Am J Obstet Gynecol 2007;196:433-44.

20. Hanprasertpong T, Phupong V. First trimester embryonic/fetal heart rate in normal pregnant women. Arch Gynecol Obstet 2006;274:257-60.

21. Louis JM, Ehrenberg HM, Collin MF, Mercer BM. Perinatal intervention and neonatal outcomes near the limit of viability. Am J Obstet Gynecol 2004;191:1398-402.

22. Weiss AR, Binns HJ, Collins JW, Jr., Deregnier RA. Decision-making in the delivery room: A survey of neonatologists. Journal of Perinatology 2007.

23. Singh J, Fanaroff J, Andrews B, et al. Resuscitation in the "gray zone" of viability: determining physician preferences and predicting infant outcomes. Pediatrics 2007;120:519-26.

24. Azria E, Tsatsaris V, Moriette G, et al. How to decide with precision, justice, and equity? Reflections on decision-making in the context of extreme prematurity. Part two: moving toward making the best possible decision: defining conditions for putting decisions into practice. J Gynecol Obstet Biol Reprod 2007;36:245-52.

25. Sayeed SA. The marginally viable newborn: legal challenges, conceptual inadequacies, and reasonableness. J Law Med Ethics 2006;34:600-610.

26. Boyle D, Carlo WA, Goldsmith J, et al. BornAlive Infants Protection Act of 2001, Public Law No. 107-207. Pediatrics 2003;111:680-1.

27. Fanaroff AA, Stoll BJ, Wright LL, et al. Trends in neonatal morbidity and mortality 
for very low birthweight infants. Am J Obstet Gynecol 2007;196:147 e141-148.

28. Russell RB, Green NS, Steiner CA, et al. Cost of Hospitalization for preterm and low birth weight infants in the United States. Pediatrics 2007;120:e1-9.

29. Haynatzka V, Peck M, Sappenfield W, et al. Racial and ethnic disparities in infant mortality rates--60 largest U.S. cities, 19951998. MMWR Morb Mortal Wkly Rep 200219;51:329-32, 343.

30. Adams MM, Kirby RS. Measuring the accuracy and completeness of linking certificates for deliveries to the same woman. Paediatr Perinat Epidemiol 2007;21:58-62.

31. Farley DO RT, Bell RM. Effects of reporting methods on infant mortality rate estimates for racial and ethnic subgroups. J Health Care Poor Underserved 1995;6:60-75.

32. Hexter AC HJ. Bias in congenital malformations information from the birth certificate. Teratology 1991;44:177-80.

33. Northam S, Polancich S, Restrepo E. Birth certificate methods in five hospitals. Public Health Nurs 2003;20:318-327.

34. Olesen AW, Westergaard JG, Thomsen SG, Olsen J. Correlation between self-reported gestational age and ultrasound measurements. Acta Obstet Gynecol Scand 2004;83: 1039-43.

35. Savitz DA, Terry Jr. JW, Dole N, et al. Comparison of pregnancy dating by last menstrual period, ultrasound scanning, and their combination. Am J Obstet Gynecol 2002;187:1660-6.

36. Mustafa G, David RJ. Comparative accuracy of clinical estimate versus menstrual gesta- tional age in computerized birth certificates. Public Health Reports 2001;116: 1521.

37. Wingate MS, Alexander GR, Buekens P, Vahratian A. Comparison of gestational age classifications: date of last menstrual period vs. clinical estimate. Ann Epidemiol 2007;17:425-30.

38. Pearl M, Wier ML, Kharrazi M. Assessing the quality of last menstrual period date on California birth records. Paediatr Perinat Epidemiol 2007;21:50-61.

39. Dietz PM, England LJ, Callaghan WM, et al. A comparison of LMP-based and ultrasound-based estimates of gestational age using linked California livebirth and prenatal screening records. Paediatr Perinat Epidemiol 2007;21:62-71.

40. Mathews TJ, MF. M. Infant mortality statistics from the 2004 period linked birth/infant death data set. Natl Vital Stat Rep 2007; 55:1-32.

41. Kirby RS. Birth certificates are an inappropriate source for identifying cases of birth defects in epidemiologic studies. Int $\mathbf{J}$ Circumpolar Health 2007;66:4.

42. Wang Y, Druschel CM, Cross PK, et al. Problems in using birth certificate files in the capture-recapture model to estimate the completeness of case ascertainment in a population-based birth defects registry in New York State. Birth Defects Res A Clin Mol Teratol 2006;76:772-7.

43. Correa-Villasenor A, Satten GA, Rolka H, et al. Random error and undercounting in birth defects surveillance data: implications for inference. Birth Defects Res A Clin Mol
Teratol 2003;67:610-6.

44. Honein MA, Paulozzi LJ. Birth defects surveillance: assessing the "gold standard". Am J Epidemiol 1999;89:1238-40.

45. Dolan SM, Gross SJ, Merkatz IR, et al. The contribution of birth defects to preterm birth and low birth weight. Obstet Gynecol 2007;110:318-24.

46. CDC, Prevention CfDCa. Compressed Mortality File 1999-2004. 2007.

47. PAHO, Organization. PAH. Regional Core Health Data Initiative. 2007.

48. Lack N, Zeitlin J, Krebs L, et al. Methodological difficulties in the comparison of indicators of perinatal health across Europe. Eur J Obstet Gynecol Reprod Biol 2003;111:S33-S44.

49. Kramer MS, Platt RW, Yang H, Haglund B, Cnattingius S, Bergsjo P. Registration artifacts in international comparisons of infant mortality. Paediatr Perinat Epidemiol 2002; $16: 16-22$.

50. Chase H. Registration Completeness and International Comparisons of Infant Mortality. Demography 1969;6:425-33

51. Oppenheimer E. Infant Mortality in Memphis: Children's Bureau, United States Department of Labor; 1936

52. Edmondson A. Born to Die - 38108 The infant death capital. Commercial Appeal 2005 March 13.

53. Mathers CD, Salomon JA, Murray CJL. Infant mortality is not an adequate summary measure of population health. J Epidemiol Community Health 2003;57:319. 